\title{
Article
}

Arq Neuropsiquiatr 2011;69(4):666-669

\section{Critical analysis of extra peritoneal antero-lateral approach for lumbar plexus}

\author{
Roberto Sérgio Martins ${ }^{1,3}$, Bernardo Assumpção Monaco², \\ Mario Gilberto Siqueira', Luciano Foroni' ${ }^{1}$, \\ Carlos Otto Heise ${ }^{1}$, Manoel Jacobsen Teixeira²
}

\begin{abstract}
Lesions of lumbar plexus are uncommon and descriptions of surgical access are derived from vertebral spine approaches. Method: The extraperitoneal anterolateral approach to the lumbar plexus was performed in six adult fresh cadavers. The difficulties on dissection were related. Results: An exposure of all distal elements of lumbar plexus was possible, but a cranial extension of the incision was needed to reach the iliohypogastric nerve in all cases. Ligation of vessels derived from common iliac artery was necessary for genitofemoral and obturator nerves exposure in two cases. The most proximal part of the lumbar roots could be identified only after dissection and clipping of most lumbar vessels. Conclusion: The extraperitoneal anterolateral approach allows appropriate exposure of terminal nerves of lumbar plexus laterallly to psoas major muscle. Cranial extension of the cutaneous incision may be necessary for exposure of iliohypogastric nerve. Roots exposure increases the risk of vascular damage.
\end{abstract}

Key words: lumbar plexus, surgical approach, peripheral nerve.

\section{Análise crítica do acesso anterolateral retroperitoneal ao plexo lombar}

\section{RESUMO}

As lesões do plexo lombar são incomuns e as descrições dos acessos cirúrgicos são derivadas de vias de acesso à coluna vertebral. Método: $A$ via extraperitoneal anterolateral foi realizada em seis cadáveres para o acesso ao plexo lombar. Eventuais dificuldades na dissecção foram relatadas. Resultados: Tal acesso permitiu a exposição dos elementos distais do plexo lombar, mas uma extensão cranial da incisão foi necessária para a exposição do nervo iliohipogástrico. Para a exposição dos nervos genitofemoral e obturador houve a necessidade da ligadura de vasos originados da artéria ilíaca comum em 2 casos. As raízes foram identificadas somente após dissecção e ligadura dos vasos lombares. Conclusão: $\bigcirc$ acesso anterolateral extraperitoneal permite uma exposição adequada dos nervos terminais do plexo lombar lateralmente ao músculo psoas maior. Uma extensão cranial da incisão pode ser necessária para exposição do nervo iliohipogástrico. A exposição das raízes implica em maior risco de lesão vascular. Palavras-chave: plexo lombar, acesso cirúrgico, nervo periférico.

\section{Correspondence \\ Roberto S. Martins Rua Maestro Cardim 592 / cj 1101 01323-001 São Paulo SP - Brasil \\ E-mail: robar@ig.com.br}

Conflicts of interest

The authors report no conflict of interest

Received 10 February 2011 Received in final form 22 March 2011 Accepted 29 March 2011
The lumbar plexus is positioned inside the psoas major muscle and is formed by ventral branches of spinal lumbar nerves from L1 to L4 with a possible contribu- tion from the subcostal nerve (T12) ${ }^{1}$. The psoas major muscle represents a fundamental reference for localization of the principal nerves originated from the 
lumbar plexus. The iliohypogastric, ilioinguinal, lateral cutaneous nerve of the thigh and femoral nerves emerge laterally to the lateral edge of this muscle, while the genitofemoral and obturator nerves emerge more medially, the first on the abdominal surface of the muscle near its medial border and the second, medially to the medial edge of the psoas major muscle ${ }^{1}$. Nerves originated from lumbar plexus course to the inferior limbs anterior to the hip joint and innervate predominantly the anterior region of thigh, while nerves derived from sacral plexus reach inferior limbs posterior to this articulation to innervate the posterior face of thigh, most of the leg and foot.

Considering the paucity of relevant data in the literature, the goal of this study is to evaluate the extra peritoneal antero-lateral approach to the lumbar plexus giving details of its limits, and relationship of its constituents, from roots to terminal nerves.

\section{METHOD}

The present study was approved by Ethics Committee of Hospital das Clinicas da Faculdade de Medicina oda Universidade de São Paulo. Six adult fresh cadavers without fixation, all male, with mean age of 61 years (range 49 to 72 years) were dissected on the Serviço de Verificação de Óbitos da Capital (SVOC). With the cadaver in the supine position, a lateral abdominal incision was made on the left side, beginning $5 \mathrm{~cm}$ distal to twelfth rib, and extending $10 \mathrm{~cm}$ obliquely, in a caudal and medial direction, entering the hypogastric region (Fig 1). If necessary the skin incision was extended in a cranial and/or caudal direction. The anterolateral abdominal wall muscles were sectioned in the same direction of the skin incision. Thus, the obliquus externus abdominis, the obliquus internus abdominis and the transversus abdominis muscles were consecutively incised allowing identification of parietal peritoneum. The transversus adbominis muscle was dissected from the parietal peritoneum by digital dissection, and the abdominal content, covered by this serous membrane, was displaced medially allowing access to the retroperitoneal space and identification of the psoas major muscle (Fig 2). Dissection proceeded laterally to this muscle with incision and resection of the iliopsoas fascia and identification of the distal nerves of the lumbar plexus. For identification of femoral nerve the interval between psoas major and iliac muscles was dissected, and for isolation of genitofemoral and obturator nerves the dissection proceeded medially and proximally on the psoas muscle. To reach the proximal lumbar plexus this muscle had to be partially or fully removed. At this stage of dissection, the difficulties on isolating neural elements were described and anatomical variations were recorded, as well as the position of nerves in relation to the psoas muscle.

\section{RESULTS}

After few modifications on the initial surgical planning all terminal nerves of lumbar plexus could be properly identified using the anterior retroperitoneal approach. In three cases the incision was not adequate to expose the iliohypogastric nerve, being necessary to extend it $3 \mathrm{~cm}$ cranially, towards the twelfth rib. The ilioinguinal and iliohypogastric nerves were single neural elements, positioned laterally to the psoas major muscle in all dissections. The lateral cutaneous nerve of the thigh (LCN) could be identified in the interval between iliac and psoas major muscles was dissected distally to the iliohypogastric nerve in all cadavers. In one case, the LCN was originated medially to the psoas major muscle, located on a diagonal course from the medial muscle edge to the inferior region of the abdominal wall. In the other

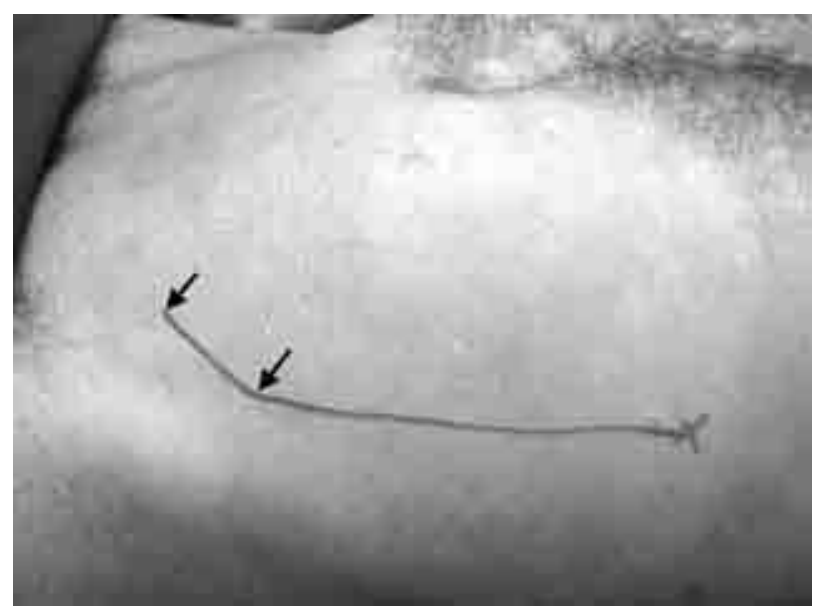

Fig 1. Photograph illustrating planned incision of the anterolateral approach to the lumbar plexus. An caudal extension was limited by the arrows.

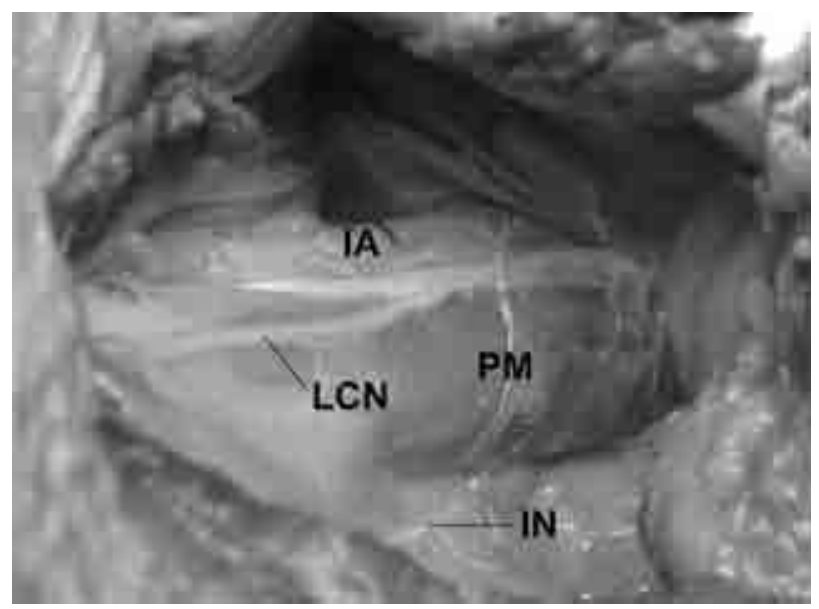

Fig 2. Surgical view of the retroperitoneal space after muscle layers section and medial displacement of the abdominal content. IA: common iliac artery; I N: iliohypogastric nerve; LCN: lateral cutaneous nerve of the thigh; PM: psoas major muscle. 


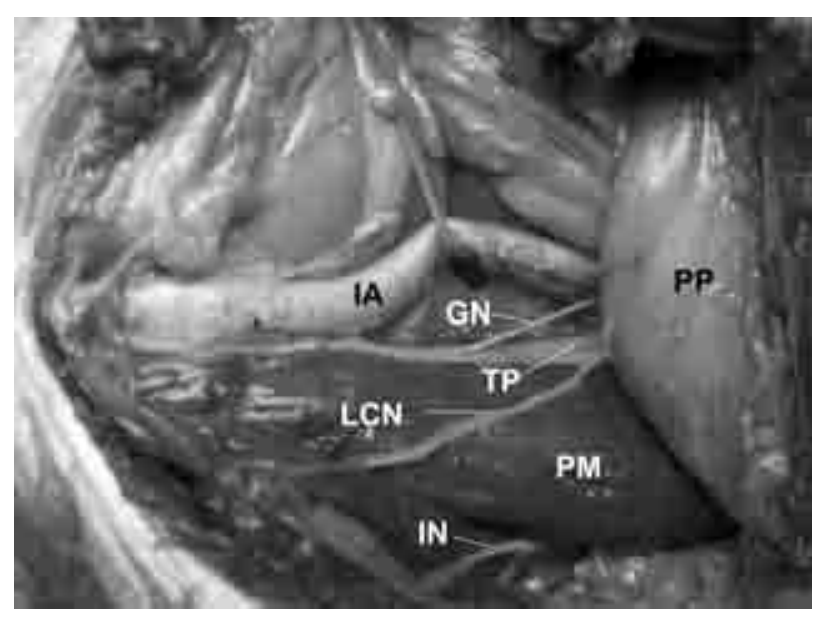

Fig 3. Surgical view of the retroperitoneal space after ressection of iliopsoas fascia. IA: common iliac artery; GN: genitofemoral nerve; IN: iliohypogastric nerve; LCN: lateral cutaneous nerve of the thigh; PM: psoas major muscle; PP: parietal peritoneum; TP: tendon of the psoas minor muscle. Note medial origin of the lateral cutaneous nerve of the thigh and genitofemoral nerve.

five cases this nerve was originated laterally to the psoas major muscle (Fig 3). In one case the femoral nerve consisted of two branches along its entire course, since its origin until its exit from the pelvic cavity. In all cases the genitofemoral nerve was identified on the medial edge of the middle third of psoas major muscle after perforating this muscle (Fig 3). This nerve was constituted as a single element in four cases and in two cases it pierced the psoas major muscle as two main branches.

For an adequate exposure of the proximal portion of the obturator and genitofemoral nerves, resection of the medial part of the psoas muscle was necessary in all cadavers. In two cases, this exposure was possible only after division of the lateral arterial branches originated from the common iliac artery. Otherwise, there was no damage to any vessel during lumbar plexus dissection laterally to psoas major muscle. For roots exposure, it was necessary to resect all psoas muscle in transverse section. In this situation, the correct identification of roots closely to the intervertebral foramens was possible only after dissection and ligation of most lumbar vessels.

\section{DISCUSSION}

The lumbar plexus is relatively well protected from external injury because of its localization on the internal surface of dorsal abdominal wall, ventrally to the vertebral transverse processes. This explains the paucity of published series on this subject ${ }^{1,2}$. Perforating objects, gunshot wounds, pelvic bone and hip fractures, retroperitoneal hemorrhage, iatrogenic lesions after abdominal and pelvic surgeries are the most common etiological factors mentioned in the literature ${ }^{2-7}$. Surgery as treat- ment of lumbar plexus lesions is uncommon ${ }^{2,8,9}$ and, because of its wide distribution, the complete exposure of the lumbar plexus by a single approach is practically impossible.

Due to the rarity of isolated injury of the lumbar plexus, the different surgical approaches are derived from those described in spinal surgery or for retroperitoneal tumor resection ${ }^{10,11}$. The surgical approaches to the lumbar plexus can be classified in anterior or posterior? In posterior approaches the patient is placed in prone position and usually a paramedian incision is used. These approaches allow exposure of proximal lumbar plexus, including the roots, its branches and proximal part of some nerves. The anterior approaches are used with the patient in lateral or supine position and allow exposure of the distal lumbar plexus. According to Johnson and Southwick, the extraperitoneal anterior approach allows good exposure of medial and inferior third of the retroperitoneal region providing access to terminal nerves of the lumbar plexus ${ }^{10}$. However, the authors recommend that the proximal incision should extend as far as the twelfth rib for exposure of the nerves situated more cranially, as iliohypogastric and ilioinguinal. Results from the present study corroborate this observation since in all cases the planned incision needed to be extended until near to the twelfth rib for a proper exposure of the iliohypogastric nerve. This occurs because the surgical field narrows from a large external view to a more focal exposure such as the iliohypogastric nerve approach. Additionally, the need for electrical stimulation or intraoperatory electrophysiological monitoring during surgery prevents the use of muscle blocking agents, which affects abdominal wall muscle displacement.

Based on literature data and on the results of this study the main advantage of the extra peritoneal anterior approach for exposure of the lumbar plexus is the direct exposure of nerves laterally to psoas major muscle. When a more medial plexus exposure is required, this reflects on more surgical manipulation and increased risk of iliac vessels damage. For example, the proximity of vascular branches to medial elements of lumbar plexus, as observed in this study, makes dissection of obturator and genitofemoral nerves more difficult. Furthermore, the anatomy of the common iliac artery can vary significantly and the presence of lateral branches, described in up $35 \%$ of the cadavers, can difficult nerve dissection ${ }^{12}$. Injury to lumbar vessels can also occur if the dissection proceeds to the root level, a potential catastrophic complication owing to the risk of spinal cord ischemia.

Besides anterolateral extraperitoneal approach, another surgical strategy that has been used to access lumbar plexus anteriorly is the transperitoneal approach, which allows wide exposure of retroperitoneal space. 
This approach is used mostly for the resection of large neural tumors. Its main disadvantage is the need of a laparotomy and the consequent potential morbidity. To avoid a possible complication, an ureteral catheter placement is recommended. This facilitates the digital identification of the ureter and prevents its damage ${ }^{13}$.

In conclusion, the extra peritoneal anterolateral approach allows adequate exposure of terminal nerves of the lumbar plexus laterally to psoas major muscle. Cranial extension of skin incision may be necessary to expose the iliohypogastric nerve and roots exposure increases the risk of vascular injury.

\section{REFERENCES}

1. Matejcík V. Anatomical variations of lumbosacral plexus. Surg Radiol Anat 2010;32:409-414.

2. Stoehr M. Traumatic and postoperative lesions of the lumbosacral plexus. Arch Neurol 1978;35:757-760.

3. Chiou-Tan FY, Kemp K Jr, Elfenbaum M, Chan KT, Song J. Lumbosacral plexopathy in gunshot wounds and motor vehicle accidents: comparison of electrophysiologic findings. Am J Phys Med Rehabil 2001;80:280-285.
4. Chiu WS. The syndrome of retroperitoneal hemorrhage and lumbar plexus neuropathy during anticoagulant therapy. South Med J 1976;69:595-599.

5. Durkin A, Sagi HC, Durham R, Flint L. Contemporary management of pelvic fractures. Am J Surg 2006;192:211-223.

6. Stevanato G, Vazzana L, Daramaras S, Trincia G, Saggiorno GC, Squintani G. Lumbosacral plexus lesions. Acta Neurochir 2007;100(Suppl):S15-S20.

7. Tung TH, Martin DZ, Novak CB, Lauryssen C, Mackinnon SE. Nerve reconstruction in lumbosacral plexopathy: case report and review of the literature. J Neurosurg (Pediatrics 1) 2005;102:86-91.

8. Verstraete KLA, Martens F, Smeets $\mathrm{P}$, et al. Traumatic lumbosacral nerve root meningoceles. The value of myelography, CT and MRI in the assessment of nerve root continuity. Neuroradiology 1989;31:425-429.

9. Lang EM, Borges J, Carlstedt T. Surgical treatment of lumbosacral plexus injuries. Neurosurg (Spine 1) 2004;1:64-71.

10. Johnson RM, Southwick WO. Surgical approaches to the lumbosacral spine. In: Rothman RH, Simeone FA (Eds). The spine. $2^{\text {nd }}$ Ed. Philadelphia PA: WB Saunders, 1982;171-187.

11. Benglis Jr DM, Vanni S, Levi AD. An anatomical study of the lumbosacral plexus as related to the minimally invasive transpsoas approach to the lumbar spine. Neurosurgery (Spine) 2009;10:139-144.

12. El Mamoun BA, Demmel U. The lateral branches of the common iliac artery. Surg Radiol Anat 1988;10:161-164.

13. Bumpass DB, Keller TC, Robinson EP, et al. Implications of Imbar plexus anatomy for removal of total discs replacements through a posterior approach. Spine 2008;33:274-278. 